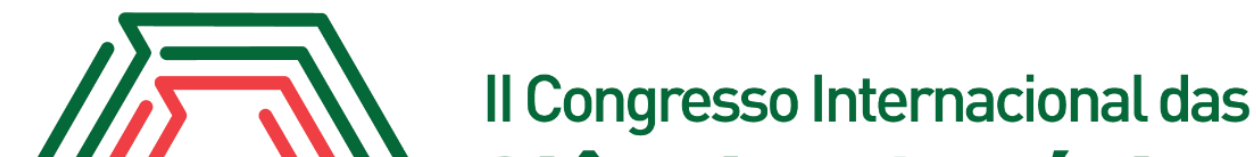 Ciências Agrárias COINTER - PDVAgro 2017
}

\section{CARACTERIZAÇÃO DE ACEROLA ORGÂNICA EM DOIS ESTÁDIOS DE MATURAÇÃO}

\author{
Apresentação: Pôster
}

\begin{abstract}
Michelle Ferreira Silva ${ }^{1}$; Ailson João Filho ${ }^{2}$; Jackson Mirellys Azevedo Souza ${ }^{3}$; Elma Machado Ataíde $^{4 ;}$ Débora Costa Bastos ${ }^{5}$.
\end{abstract}

\section{Introdução}

A cultura da aceroleira (Malpighia glabra L.) foi introduzida no Brasil na década de 50 pela Universidade Federal Rural de Pernambuco, mas somente em meados da década de 80 que passou a ser cultivada comercialmente em diversas regiões do país. A área com esta cultura é estimada em 10 mil hectares, com destaque para os estados da Bahia, Ceará, Paraíba e Pernambuco, os quais são responsáveis por cerca de $60 \%$ da produção brasileira (FURLANETO; NASSER, 2015).

Esta frutífera exótica tem se destacado devido ser apreciada pelos consumidores pelo valor farmacológico e alimentício, uma vez que é considerada como fonte alternativa de vitamina $\mathrm{C}$ a baixo custo (CARPENTIERI PÍPOLO et al, 2000). Em vista do seu grande potencial de mercado, o seu cultivo vem se expandindo nas diversas regiões do País.

A colheita das acerolas destinadas ao consumo "in natura" ou processadas devem ser feitas de forma criteriosa, com colhedores treinados, especialmente para os frutos destinados à exportação que devem ser colhidos no estádio "de vez”, visto que frutos maduros apresentam curto período de conservação, resultando em perdas no armazenamento e na comercialização. A determinação do ponto adequado de colheita é uma etapa importante para a conservação dos frutos, visto que está diretamente ligada a qualidade (CHITARRA \& CHITARRA, 2005). Face ao exposto, objetivou-se avaliar as características físicas e físico-químicas de acerola orgânica em dois estádios de maturação.

\footnotetext{
1 Graduanda em Agronomia, Bolsista Apoio Acadêmico da Universidade Federal Rural de Pernambuco, Serra Talhada, PE, michellefs2008@hotmail.com

${ }^{2}$ Graduando em Agronomia, Universidade Federal Rural de Pernambuco-Campus Serra Talhada, ailsonjoaotec@outlook.com.br

3 Pós-doutorando em Agronomia-Horticultura, Faculdade de Ciências Agronômicas da UNESP- Botucatu-SP, jackson.mirellys@hotmail.com

${ }^{4}$ Professora Adjunto - Fruticultura, Universidade Federal Rural de Pernambuco-Campus Serra Talhada, elmaataide@yahoo.com.br

${ }^{5}$ Doutora, Embrapa semiárido, debora.bastos@embrapa.br
} 


\section{Fundamentação Teórica}

A aceroleira é originária das Antilhas, América Central, possui porte arbustivo tipo glabro, ramos densos e espalhados, folhas opostas, com pecíolo curto, ovaladas e elíptico-pecioladas, medindo entre $2,5 \mathrm{~cm}$ e $7,5 \mathrm{~cm}$, atinge altura média de 2 a 3 metros.

Conhecida como cerejeira das Antilhas, essa planta é rústica, os frutos se destacam pelo grande potencial nutricional e econômico. No Brasil, essa cultura oferece grandes possibilidades de sucesso pelas condições climáticas favoráveis, (SOUZA et al, 2006), o que tem favorecido o aumento do número de produtores nos diferentes estados.

A acerola é consumida in natura, processada, na forma de sucos, sorvetes, geléias, licores, doce em calda, utilizada como matéria-prima na indústria farmacêutica para produção de xarope, cápsulas como suplemento alimentar, na produção de cremes e gomas de mascar (RITZINGER et al, 2011). O aumento do consumo e o interesse das suas potencialidades econômicas é devido, principalmente, pelo seu alto teor de vitamina $\mathrm{C}$, o que justifica o seu lugar privilegiado diante do mercado consumidor (GOMES, 2000). Em vista da sua importância econômica, estudos das características físicas e físico-químicas da acerola em diferente estádio de maturação são importantes.

\section{Metodologia}

O trabalho foi realizado no Laboratório de Química da Universidade Federal Rural de Pernambuco, Unidade Acadêmica de Serra Talhada, utilizando-se acerolas oriundas de plantas conduzidas em sistema orgânico na área experimental da Universidade, em Serra Talhada-PE.

Os frutos foram colhidos nos estádios de maturação "De vez" e "Maduro", acondicionados em recipientes plásticos, transportados para o Laboratório, em seguida foram selecionados e lavados. O delineamento experimental foi em bloco casualizado, utilizando 24 frutos por unidade experimental, com 10 repetições, totalizando 240 frutos para cada estádio de maturação.

As características físicas dos frutos foram determinadas através da massa do fruto, da semente e da casca, da polpa e casca (g), com auxilio de balança analítica com precisão de 0,001g; o rendimento de polpa (\%), diâmetros longitudinal e transversal $(\mathrm{cm})$ e formato do fruto (DL/DT).

A caracterização físico-química foi determinada pelos teores de sólidos solúveis (SS), expresso em ( ${ }^{\circ}$ Brix), com refratômetro digital Atago; acidez titulável (AT), expressa em porcentagem de ácido cítrico, com titulação com $\mathrm{NaOH}$ a $0,1 \mathrm{~N}$, com os indicadores fenolftaleína 
para os frutos "De vez" e o azul-de-bromotimol para os frutos no estádio Maduro. O pH, aferido com pHmetro, índice de maturação, calculado pela relação entre SS e AT e o índice tecnológico, obtido pela expressão sólido solúvel x rendimento de polpa/100.

Os dados médios das características avaliadas foram submetidos à análise descritiva, calculando-se as médias das características avaliadas e seus respectivos desvios padrão.

\section{Resultados e Discussões}

As análises físicas dos frutos em estádio de maturação "Maduro" quando comparadas às de estádio de maturação "De vez" apresentaram maiores médias de massa do fruto (MF), massa de polpa e casca (MPC), rendimento de polpa (RP), diâmetro longitudinal (DL) e diâmetro transversal (DT) (Tabela 1). Embora a média de massa de sementes dos frutos maduros tenha sido superior, o desvio padrão também foi mais alto, em contrapartida o desvio padrão dos frutos “de vez", para esta mesma característica, foi mais baixo, de modo pode-se dizer que a diferença entre os dois estádios de maturação não foi tão acentuada. Já para as demais características físicas em que os frutos maduros foram superiores, mesmo considerando os desvios padrão, verifica-se que as médias dos frutos maduros foram superiores de forma há não haver sobreposição entre os valores de ambos os estádios. As maiores médias para as características físicas dos frutos maduros eram esperadas visto que estes frutos permaneceram por maior período na planta, e consequentemente, receberam maior quantidade de nutrientes e fotoassimilados da planta mãe, continuando seu desenvolvimento. Os resultados encontrados para os diâmetros para o estádio de maturação maduro (DL e DT) corroboram com os valores encontrados por Batista et al.(2000), os quais observaram médias de diâmetro transversal e longitudinal de frutos maduros de acerola de, respectivamente, $2,14 \mathrm{~cm} \mathrm{e}$ $1,19 \mathrm{~cm}$. Dentre todas as características físicas, apenas o formato do fruto, considerando o desvio padrão, foi praticamente igual em ambos os estádios de maturação, tal resultado demonstra que ainda que aumentem de tamanho, após atingir o estádio de maturação "Maduro", os frutos permanecem com o mesmo formato.

Tabela 1. Médias e desvio padrão (DP) de massa do fruto (MF), massa da semente (MS), massa de polpa e casca (MPC), rendimento de polpa e casca (RPC), diâmetro longitudinal (DL), diâmetro transversal (DT) e formato (FF) de frutos de acerola em dois estádios de maturação. Serra Talhada-PE, 2017. Fonte: Própria

\begin{tabular}{cccccccc}
\hline $\begin{array}{c}\text { Estádio de } \\
\text { maturação }\end{array}$ & $\begin{array}{c}\text { MF } \\
(\mathbf{g})\end{array}$ & $\begin{array}{c}\text { MS } \\
(\mathbf{g})\end{array}$ & $\begin{array}{c}\text { MCP } \\
(\mathbf{g})\end{array}$ & $\begin{array}{c}\text { RPC } \\
(\boldsymbol{\%})\end{array}$ & $\begin{array}{c}\text { DL } \\
(\mathbf{c m})\end{array}$ & $\begin{array}{c}\text { DT } \\
(\mathbf{c m})\end{array}$ & $\begin{array}{c}\text { FF } \\
(\mathbf{D L} / \mathbf{D T})\end{array}$ \\
\hline Maduro & 153,40 & 94,83 & 7,92 & 145,48 & 1,93 & 2,40 & 0,81
\end{tabular}




\begin{tabular}{cccccccc} 
DP & $\pm 6,61$ & $\pm 1,64$ & $\pm 2,5$ & $\pm 7,11$ & $\pm 0,08$ & $\pm 0,07$ & $\pm 0,03$ \\
De vez & 114,37 & 96,67 & 3,80 & 110,57 & 1,79 & 2,19 & 0,82 \\
DP & $\pm 9,93$ & $\pm 0,37$ & $\pm 0,37$ & $\pm 9,81$ & $\pm 0,07$ & $\pm 0,07$ & $\pm 0,02$ \\
\hline Média geral & 133,89 & 95,75 & 5,86 & 128,02 & 1,86 & 2,30 & 0,81 \\
\hline
\end{tabular}

Quando avaliadas as características físico-químicas (Tabela 2), observou-se que os frutos maduros apresentaram maiores médias de sólidos solúveis (SS), acidez titulável (AT), índice de maturação (IM) e índice tecnológico (IT) (Tabela 2). Somente para o pH as médias dos frutos "De vez" foi maior, no entanto, considerando o desvio padrão, pode-se dizer que o $\mathrm{pH}$, em ambos os estádios, foram iguais, assim como para a acidez, cujas médias para ambos não foram muito diferentes. Para as características SS e IM dos frutos maduros, verificou-se além de médias maiores, também maiores desvios padrão, todavia, não suficiente para sobrepor as médias em ambos os estádios, demonstrando que as médias dos frutos maduros são realmente superiores.

Tabela 2. Médias e desvio padrão (DP) de pH, sólidos solúveis (SS), acidez titulável (AT), índice de maturação (IM) e índice tecnológico (IT) de frutos de acerola em dois estádios de maturação. Serra Talhada-PE, 2017. Fonte: Própria

\begin{tabular}{cccccc}
\hline Tratamento & $\mathbf{p H}$ & $\begin{array}{c}\text { Sólidos } \\
\text { solúveis } \\
\left({ }^{\circ} \text { Brix }\right)\end{array}$ & $\begin{array}{c}\text { Acidez } \\
\text { titulável }(\% \\
\text { de ác.cítrico) }\end{array}$ & $\begin{array}{c}\text { Índice de } \\
\text { Maturação }\end{array}$ & $\begin{array}{c}\text { Índice } \\
\text { tecnológico }\end{array}$ \\
\hline Maduro & 3,32 & 8,17 & 1,24 & 6,59 & 7,74 \\
DP & $\pm 0,03$ & $\pm 0,44$ & $\pm 0,07$ & $\pm 0,42$ & $\pm 0,36$ \\
De vez & 3,36 & 6,25 & 1,22 & 5,15 & 6,04 \\
DP & $\pm 0,04$ & $\pm 0,42$ & $\pm 0,09$ & $\pm 0,25$ & $\pm 0,4$ \\
\hline Média & 3,34 & 7,21 & 1,23 & 5,87 & 6,89 \\
\hline
\end{tabular}

De acordo com Chitarra e Chitarra (2005) a avaliação do índice de maturação permite ter um real indicativo do sabor do fruto e uma vez que se refere à relação entre os sólidos solúveis e a acidez titulável, pode-se dizer que é afetado por todos os fatores que interferem nestas características, ambientais ou fisiológicos. Além da importância para o sabor dos frutos, os ácidos orgânicos e sólidos solúveis são também produtos para a respiração dos frutos, configurando importância para a conservação destes frutos no período pós-colheita (Chitarra e Chitarra, 2005). Deste modo, os frutos maduros destacam-se por apresentarem maiores médias para estas características.

\section{Conclusões}

As acerolas no estádio de maturação "maduro" apresentam melhores características físicas e físico-químicas em relação ao estádio "de vez", sobretudo para massa do fruto, rendimento de polpa, diâmetros, sólidos solúveis, índice de maturação e índice tecnológico. 


\section{Referências}

BATISTA, M. de S.; FIGUERÊDO, R. M. F de, QUIEROZ, A. J. de M. Parâmetros físicos e químicos da acerola (Malpighia punicifolia, L.) em diferentes fases de maturação. Revista Brasileira de Produtos Agroindustriais, Campina Grande, v. 2, n. 2, p. 19-24, 2000.

CARPENTIERI-PIPOLO, V,; DESTRO, D,; PRETE. C.E.C.; GONZALES, M.G.N.; POPPER, I.; ZANATTA, S.; SILVA, F.A.M. Seleção de genótipos parentais de acerola com base na divergência genética multivariada. Pesquisa agropecuária brasileira. Brasília, v. 35, n. 8, 2000.

CHITARRA, M.I.F.; CHITARRA, A.B. Pós-colheita de frutas e hortaliças: fisiologia e manuseio. 2. ed. rev. e ampl. Lavras: UFLA, 2005. 785 p.

FLORI ET AL. 2012- A CULTURA DA ACEROLA, Empresa Brasileira de Pesquisa Agropecuária Embrapa Semiárido; Ministério da Agricultura e do Abastecimento;3a edição revista e ampliada Embrapa ,Brasília, DF-2012

FURLANETO, F.P.B.; NASSER, M.D. Panorama da cultura da acerola no estado de São Paulo. Pesquisa \& Tecnologia, vol. 12, n. 1, 2015.

GOMES, J. E.; PERECIN, D.; MARTINS, A.B.G.; FERRAUDO, A. S. Análises de agrupamentos e de componentes principais no processo seletivo em genótipos de aceroleira (Malphigiaemarginata D.C). Revista Brasileira de Fruticultura, Jaboticabal, v. 22, n.1, p. 36-39, 2000.

MANSUR, C. J. R.; MORAES, J.A.P.V; BURITY, H. A; SILVA, J.J.F- Extraído da Dissertação de doutorado da primeira autora, apresentada à Universidade Federal de São Carlos (UFSCar), São Carlos, SP.Pesquisa agropecuária brasileira., Brasília, v. 37, n. 4, p. 463-470, abr. 2002

SOUZA, M. J.; GUIMARÃES, M. C. A.; GUIMARÃES, C. D. L.; FREITAS, W. S.; OLIVEIRA, A. M. S. Potencial agroclimático para a cultura da acerola no Estado de Minas Gerais. Revista Brasileira Agrícola e Ambiental, Campina Grande, v. 10, n. 2, 2006. 